\title{
DNA-Binding Transferrin Conjugates as Functional Gene-Delivery Agents: Synthesis by Linkage of Polylysine or Ethidium Homodimer to the Transferrin Carbohydrate Moiety
}

\author{
Ernst Wagner," Matt Cotten, Karl Mechtler, Helen Kirlappos, and Max L. Birnstiel \\ Research Institute of Molecular Pathology, Dr. Bohr-Gasse 7, A-1030 Vienna, Austria. Received March 26, 1991
}

\begin{abstract}
We have previously demonstrated that transferrin-polycation conjugates are efficient carrier molecules for the introduction of genes into eucariotic cells. We describe here a more specific method for conjugation of transferrin with DNA-binding compounds involving attachment at the transferrin carbohydrate moiety. We used the polycation poly(L-lysine) or the DNA intercalator, ethidium homodimer as DNAbinding domains. Successful transferrin-receptor-mediated delivery and expression of the Photinus pyralis luciferase gene in $\mathrm{K} 562$ cells has been shown with these new transferrin conjugates. The activity of the transferrin-ethidium homodimer (TfEtD) conjugates is low relative to transferrin-polylysine conjugates; probably because of incomplete condensation of the DNA. However, DNA delivery with TfEtD is drastically improved when ternary complexes of the DNA with TfEtD and the DNA condensing agent polylysine are prepared. The gene delivery with the carbohydrate-linked transferrin-polylysine conjugates is equal or superior to described conjugates containing disulfide linkage. The new ligation method facilitates the synthesis of large quantities (>100 mg) of conjugates.
\end{abstract}

\section{INTRODUCTION}

Transferrin-polycation conjugates are efficient carriers for the uptake of DNA into eucariotic cells (1). This gene transfer technique, termed transferrinfection, is based on receptor-mediated endocytosis of DNA complexed with polycation-transferrin conjugates $(2,3)$. Our initial conjugate synthesis (1) involved the modification of one to two amino groups on the transferrin molecule with the bifunctional reagent succinimidyl 3-(2-pyridyldithio)propionate (SPDP), followed by ligation to similarly modified polycations (polylysine or protamine) through the formation of disulfide bonds. Because there are more than 50 lysines on the large (about $80 \mathrm{kDa}$ ) transferrin protein, the actual site (or sites) of ligation to the polycation is unknown with this method.

In this paper we describe the synthesis of new transferrin conjugates that are ligated with DNA-binding compounds in a specific manner through modification of the transferrin carbohydrate moiety. The conjugates thus obtained are free of any groups derived from chemical linking agents, since the connecting atoms are already present within the starting compounds. The carbohydrate group acts as a natural spacer that puts a 32 -atom distance between the transferrin and the DNA binding moiety. This spacer effect may be important for appropriate presentation of the ligand to its receptor. As a DNA-binding compound, the polycation polylysine was used, similar to the use described in ref 1 or to the asialo-orosomucoid conjugates prepared by $\mathrm{Wu}$ and $\mathrm{Wu}(4)$. We have also prepared a novel type of transferrin conjugate that contains the DNA intercalator ethidium homodimer (5) as the DNAbinding group and demonstrate successful receptormediated gene delivery with these conjugates.

\section{EXPERIMENTAL PROCEDURES}

Human transferrin (iron-free), conalbumin (iron-free), and poly(L-lysine) were obtained from Sigma. Liquid chro-

\footnotetext{
${ }^{1}$ Abbreviations used: FITC, fluorescein isothiocyanate; TfEtD, transferrin-ethidium homodimer conjugate; TfpL, transferrinpoly(L-lysine) conjugate; HEPES, 4-(2-hydroxyethyl)-1-piperazineethanesulfonic acid.
}

matography was performed with a Merck-Hitachi L-6210 pump, a L-4200 UV-vis detector, and a Kontron SFM25 fluorescence detector.

Quantitative Assays. Polylysine content of fractions was estimated spectrophotometrically by ninhydrin assay and in the case of FITC-labeled polylysine by absorption at $495 \mathrm{~nm}$. The amount of dithiopyridine linkers in modified transferrin was determined after reduction of an aliquot with dithiothreitol followed by absorption measurement of released pyridine-2-thione at $340 \mathrm{~nm}$. The amount of free mercapto groups was determined with $5,5^{\prime}$ dithiobis (2-nitrobenzoic acid) (6) and measurement at 412 $\mathrm{nm}$. The transferrin content of fractions was determined by UV measurement at $280 \mathrm{~nm}$ and correction of the value (where necessary) by substraction of the corresponding UV absorption of FITC, dithiopyridine, or buffer at 280 $\mathrm{nm}$. The content of sialic acids in transferrin was determined by a thiobarbituric acid assay (7).

Transferrin-Polylysine Conjugate Synthesis. A solution of $102 \mathrm{mg}(1.28 \mu \mathrm{mol})$ of transferrin (human, ironfree) in $3 \mathrm{~mL}$ of a $30 \mathrm{mM}$ sodium acetate buffer ( $\mathrm{pH} 5$ ) was subjected to gel filtration on a Sephadex G-25 (Pharmacia) column. The resulting $3.8 \mathrm{~mL}$ of solution was cooled to $0^{\circ} \mathrm{C}$ and $80 \mu \mathrm{L}$ of a $30 \mathrm{mM}$ sodium acetate buffer (pH 5) containing $4 \mathrm{mg}(19 \mu \mathrm{mol})$ of sodium periodate was added. The mixture was kept in an ice bath and in the dark for $90 \mathrm{~min}$. For removal of the low molecular weight products an additional gel filtration (Sephadex G-25, 30 $\mathrm{mM}$ sodium acetate buffer, $\mathrm{pH} 5$ ) was performed; this yielded a solution containing about $82 \mathrm{mg}(1.03 \mu \mathrm{mol})$ of oxidized transferrin (monitoring: UV absorption at 280 $\mathrm{nm}$ and ninhydrin assay). In order to detect the oxidized aldehyde-containing form that gives a color reaction upon staining with anisaldehyde reagent, samples were dropped on a silica gel thin-layer plate, dried, immersed into $p$-anisaldehyde/sulfuric acid/ethanol (1/1/18), dried, and heated. The modified transferrin solution was promptly added (within 10-15 min) to a solution containing 0.50 $\mu \mathrm{mol}$ of fluorescent labeled poly(L-lysine) with an average chain length of 300 lysine monomers in $4.5 \mathrm{~mL}$ of $100 \mathrm{mM}$ sodium acetate ( $\mathrm{pH} \mathrm{5)}$ with vigorously mixing at room temperature. [The labeled poly(L-lysine) was derived by 


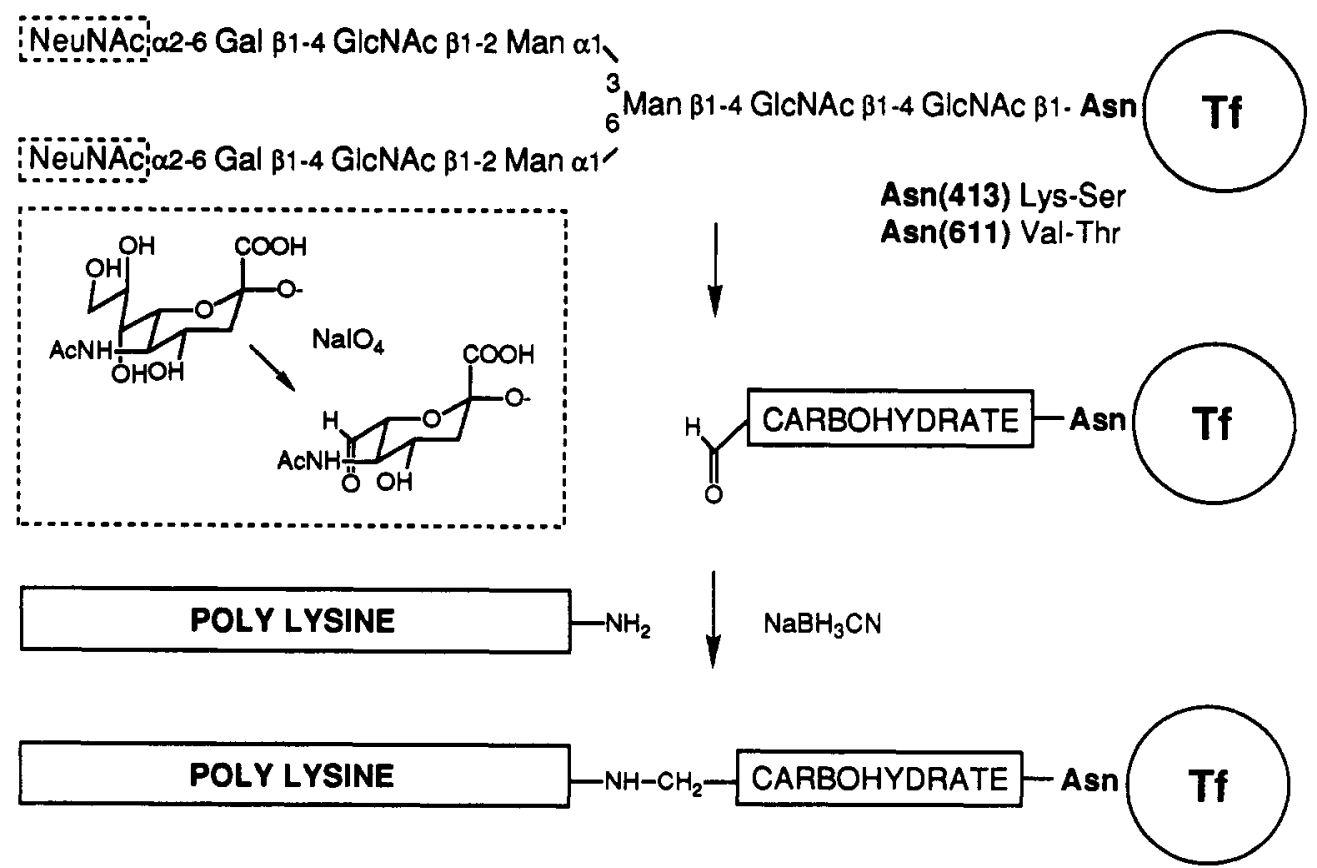

Figure 1. Conjugation via transferrin glycosylation sites. The molecular structure of sialic acid ( $N$-acetylneuraminic acid, NeuNAc) and its oxidation with sodium periodate is shown within the dashed box. Tf, transferrin.

reacting $34 \mathrm{mg}$ of hydrobromide salt with $130 \mu \mathrm{g}$ of fluorescein isothiocyanate in sodium bicarbonate buffer (pH 9) for $3 \mathrm{~h}$ and subsequent gel filtration.] The $\mathrm{pH}$ of the mixed solution was brought to 7.5 by addition of $1 \mathrm{M}$ sodium bicarbonate after $20 \mathrm{~min}$; four portions of $9.5 \mathrm{mg}$ $(150 \mu \mathrm{mol})$ of sodium cyanoborohydride each were added at 1 -h intervals. After $18 \mathrm{~h}, 1.9 \mathrm{~mL}$ of $5 \mathrm{M}$ sodium chloride were added to bring the solution to an overall salt concentration of about $0.75 \mathrm{M}$. The reaction mixture was loaded on a cation-exchange column (Pharmacia Mono S HR 10/10) and was fractionated with a salt gradient from 0.75 to $2.5 \mathrm{M}$ sodium chloride with a constant content of $25 \mathrm{mM}$ HEPES (pH 7.3). The high salt concentration during the loading of the column and at the beginning of the gradient was essential for the efficient recovery of the polycation conjugates. Some transferrin protein (about $30 \%$ ), together with a weak fluorescence activity, eluted in the flowthrough; the major amount of fluorescent conjugate eluted between 1.35 and $1.9 \mathrm{M}$ salt (see Figure 2) and was pooled into three fractions. These, after dialysis against $2 \times 2 \mathrm{~L}$ of $25 \mathrm{mM}$ HEPES ( $\mathrm{pH} 7.3$ ), yielded (in order of elution) fraction TfpL300A containing $19 \mathrm{mg}(0.24$ $\mu \mathrm{mol}$ ) of transferrin modified with $80 \mathrm{nmol}$ of polylysine, fraction TfpL300B containing $27 \mathrm{mg}(0.34 \mu \mathrm{mol})$ of transferrin modified with $150 \mathrm{nmol}$ of polylysine, and fraction TfpL300C containing $5 \mathrm{mg}(62 \mathrm{nmol})$ of transferrin modified with $80 \mathrm{nmol}$ of polylysine. The overall yield of these conjugates based on transferrin was $50 \%$, based on polylysine, $62 \%$.

Transferrin conjugates, unless immediately used, were stored (after shock-freezing in liquid nitrogen) at $-20^{\circ} \mathrm{C}$ for up to several months in the iron-free form. Before iron incorporation, samples (ca. $0.5-1.5 \mathrm{mg}$ ) were brought to physiological salt concentration $(150 \mathrm{mM})$ by addition of sodium chloride; the iron incorporation was performed by addition of $6 \mu \mathrm{L}$ of $10 \mathrm{mM}$ iron(III) citrate buffer (containing $200 \mathrm{mM}$ citrate and adjusted to $\mathrm{pH} 7.8$ by sodium bicarbonate addition)/mg of transferrin content. The iron-loaded conjugates were used for DNA-complex formation as described below. To limit the deterioration of the conjugates that often occurs upon several freezethaw cycles, the conjugates were divided into convenient

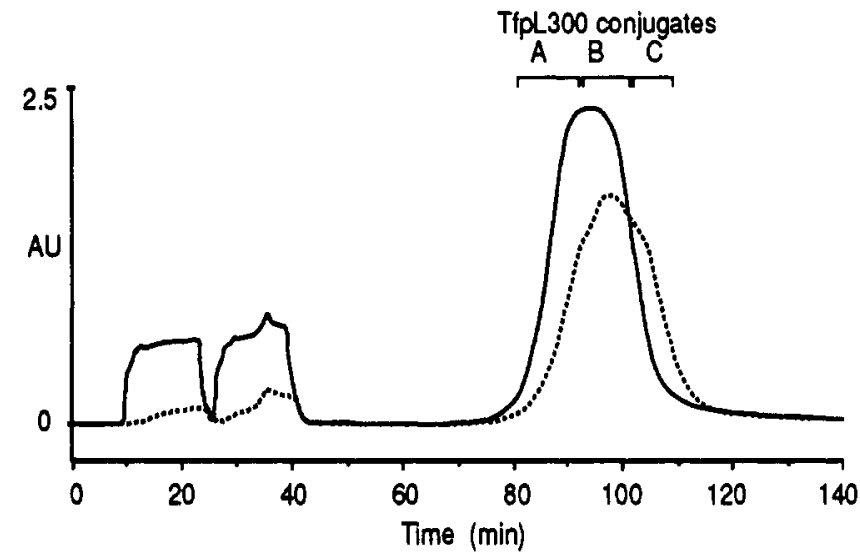

Figure 2. Isolation of transferrin-polylysine conjugates by cation-exchange chromatography. The crude reaction mixture was loaded in two portions (containing $0.75 \mathrm{M}$ salt) onto a $\mathrm{Phar}$ macia Mono $S$ column, and conjugate fractions $A, B$, and $C$ eluting between 1.35 and $1.9 \mathrm{M}$ salt were collected:,$- \mathrm{UV}$ absorption at $280 \mathrm{~nm} ; \cdot-$, fluorescence at $520 \mathrm{~nm}$.

small aliquots, shock-frozen in liquid nitrogen (or dry ice/ ethanol), and kept at $-20^{\circ} \mathrm{C}$.

Transferrin-Ethidium Homodimer Conjugate (TfEtD) Synthesis. Oxidation of $32 \mathrm{mg}(0.4 \mu \mathrm{mol})$ of transferrin (human, iron-free) with periodate was performed as described above; gel filtration (Sephadex G-25, $30 \mathrm{mM}$ sodium acetate buffer $\mathrm{pH}$ 5) yielded a $1.9 \mathrm{~mL}$ solution containing about $20 \mathrm{mg}(0.25 \mu \mathrm{mol})$ of oxidized transferrin. The transferrin was added to a solution containing $1 \mathrm{mg}$ ( $1.17 \mu \mathrm{mol})$ of ethidium homodimer $\left(5,5^{\prime}\right.$ diazadecamethylenebis(3,8-diamino-6-phenylphenanthridium) dichloride dihydrochloride, E-1169, Molecular Probes) in $1.2 \mathrm{~mL}$ of water. The mixture was kept in the dark, the $\mathrm{pH}$ of the solution was brought to 7.3 by addition of HEPES buffer, and to the mixture were added two portions of 1 $\mathrm{mg}(16 \mu \mathrm{mol})$ of sodium cyanoborohydride in $50 \mu \mathrm{L}$ of water with a 4 -h interval between portions. The reaction mixture was left at room temperature in the dark for 2 days and then was subjected to gel filtration (Sephadex G-25, $50 \mathrm{mM}$ HEPES buffer $\mathrm{pH}$ 7.3). In this step (according to UV absorption at $495 \mathrm{~nm}$ ) about $200 \mu \mathrm{g}$ of 
unconjugated ethidium dimer together with other low molecular weight components were removed. The final volume of conjugate solution was $4.1 \mathrm{~mL}$. One-third of the solution was used for preliminary purification experiments. The remainder $(2.7 \mathrm{~mL})$ was diluted with $0.6 \mathrm{M}$ guanidinium hydrochloride (buffered with sodium acetate to $\mathrm{pH}$ 5) and loaded on a hydrophobic-interaction column (phenyl-Sepharose CL-4B, Pharmacia; $100 \times 8 \mathrm{~mm}$, ca. $4.5 \mathrm{~mL}$ ). A slightly pink solution eluted in the flowthrough that also contained about $1.5 \mathrm{mg}$ of transferrin. The violet conjugates remained on the column and, after a wash with $50 \mathrm{~mL}$ of $0.6 \mathrm{M}$ guanidinium hydrochloride, were eluted with $0.6 \mathrm{M}$ guanidinium hydrochloride containing first $2 \%$ and then $3 \%$ octyl glucopyranoside (Sigma). The conjugates were collected as two subsequent eluted fractions ( 7 and $27.5 \mathrm{~mL}$ ), dialyzed against $2 \mathrm{~L}$ of $200 \mathrm{mM}$ guanidinium hydrochloride for 3 days, then concentrated with a Speedvac (Savant) to a volume of about $3 \mathrm{~mL}$ each, and again dialyzed against $2 \times 2 \mathrm{~L}$ of $25 \mathrm{mM}$ HEPES buffer ( $\mathrm{pH} 7.3$ ) for 2 days. This procedure yielded (although there was some loss of material due to the extensive dialysis) two transferrin-ethidium dimer conjugate fractions containing $2 \mathrm{mg}$ of transferrin each (according both to ninhydrin assay and Bio-Rad protein assay (Bio-Rad)); the two violet fractions had $0.42 \mathrm{AU}$ $(522 \mathrm{~nm})$ and $0.68 \mathrm{AU}(516 \mathrm{~nm})$, respectively; as the transferrin conjugated ethidium dimer had changed UV absorbtion characteristics (ethidium homodimer: $1 \mathrm{mg}$ corresponds to about $10 \mathrm{AU}(495 \mathrm{~nm})$ at $\mathrm{pH} 7.3)$, the exact content of conjugated ethidium dimer within the transferrin conjugates could not be determined. Iron incorporation was performed as described for the transferrinpolylysine conjugates.

DNA Complex Formation and Transfections. K562 cells were grown in suspension in RPMI medium plus $10 \%$ FCS, 100 units $/ \mathrm{mL}$ penicillin, $100 \mu \mathrm{g} / \mathrm{mL}$ streptomycin, and $2 \mathrm{mM}$ glutamine, reaching a density of 500000 cells/ $\mathrm{mL}$. Cells were prepared for transfection as previously described (3). To increase the surface presentation of transferrin receptor, the cells were placed, $20 \mathrm{~h}$ before transfection, in fresh medium containing $50 \mu \mathrm{M}$ desferrioxamine (Sigma) at about 200000 cells $/ \mathrm{mL}$. The desferrioxamine pretreatment raises the transferrin receptor levels ca. 5-fold, resulting in an increase in DNA delivery (3). The morning of the transfection, the cells were collected, resuspended in fresh medium containing $10 \%$ fetal calf serum (plus $50 \mu \mathrm{M}$ desferrioxamine) at 250000 cells per $\mathrm{mL}$, and placed in a 24-well dish, $2 \mathrm{~mL}$ per well.

Six micrograms of the DNA plasmid pRSVL [ containing the $P$. pyralis luciferase gene under the control of the Rous sarcoma virus long terminal repeat enhancer/ promoter (8)] in $330 \mu \mathrm{L}$ of $\mathrm{HBS}(150 \mathrm{mM} \mathrm{NaCl}, 20 \mathrm{mM}$ HEPES 7.3) were mixed with various amounts of $\mathrm{TfpL}$ conjugate in $170 \mu \mathrm{L}$ of $\mathrm{HBS}$ as specified in Figure 3 . After $30 \mathrm{~min}$ at room temperature the $500-\mu \mathrm{L}$ mixture was added to $\mathrm{K} 562$ cells. Chloroquine was added to the $2-\mathrm{mL}$ cell sample ( $100 \mu \mathrm{M}$ final concentration) about $5-10 \mathrm{~min}$ before adding the 500- $\mu \mathrm{L} \mathrm{DNA/conjugate} \mathrm{sample.} \mathrm{After} \mathrm{a} \mathrm{4-h}$ incubation at $37^{\circ} \mathrm{C}$, the cells were washed into prewarmed, fresh medium (without chloroquine) and incubated at 37 ${ }^{\circ} \mathrm{C}$. The cells were harvested $20 \mathrm{~h}$ after transfection and extracts were prepared. Aliquots of cell extracts, standardized for protein content, were assayed for luciferase activity as described (3); see Figure 3.

Complexes of DNA and transferrin-ethidium dimer conjugate were formed as described for the TfpL conjugates, by mixing a $330-\mu \mathrm{L}$ solution of $6 \mu \mathrm{g}$ of pRSVL in HBS with a $170-\mu \mathrm{L}$ solution of various amounts of TfEtD

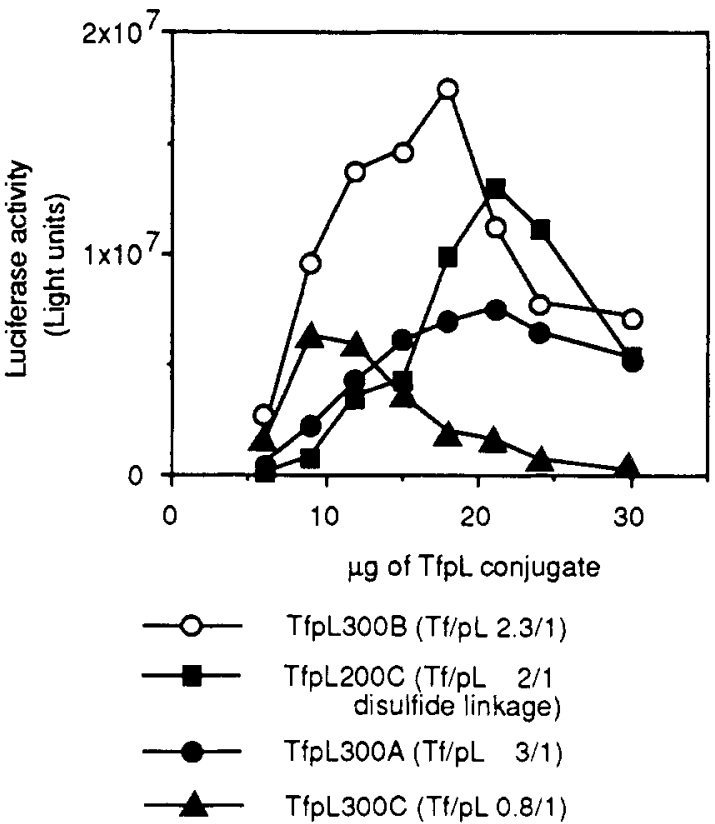

Figure 3. Luciferase gene expression mediated by transferrinfection in K562 cells. For complex formation with $6 \mu \mathrm{g}$ of pRSVL plasmid DNA, 6-30 $\mu \mathrm{g}$ of the carbohydrate-linked transferrinpolylysine conjugate fractions TfpL $300 \mathrm{~A},-\mathrm{B}$, or $-\mathrm{C}$ were used. DNA complexes with the most active conjugate fraction TfpL $200 \mathrm{C}$ deriving from a ligation procedure via disulfide bonds (16) were prepared in parallel. The gene delivery resulting from the various complexes in $\mathrm{K} 562$ cells $20 \mathrm{~h}$ after the transfection was determined by assaying aliquots of cell extracts standardized for protein content. The values shown represent the activity of the entire cellular samples of about 500000 cells.

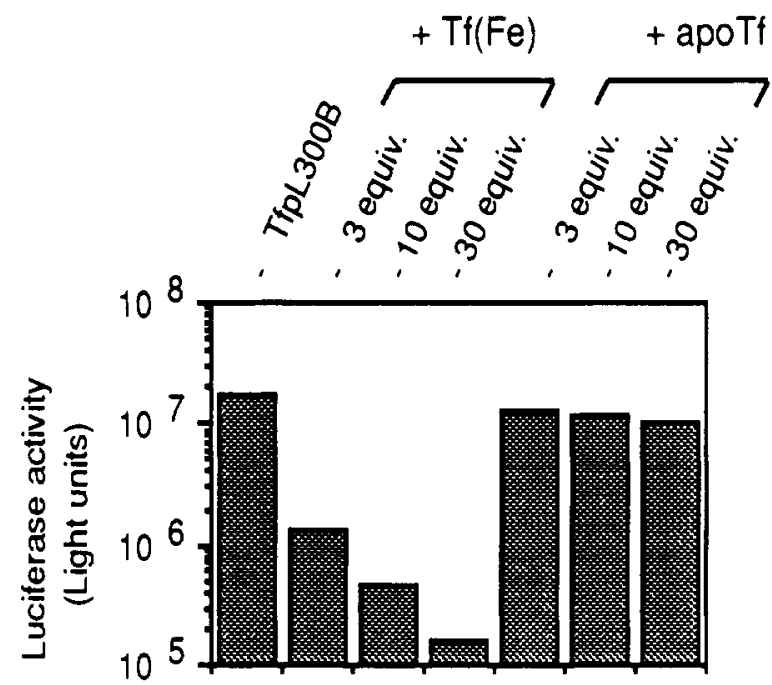

Figure 4. Transferrinfection is competitively inhibited by ironloaded transferrin. Transferrinfection with complexes of $6 \mu \mathrm{g}$ of pRSVL plasmid DNA and $18 \mu \mathrm{g}$ of TfpL $300 \mathrm{~B}$ was performed in a similar fashion as described in Figure 3 and Experimental Procedures, with the difference that indicated amounts of either iron-loaded transferrin [ $\mathrm{Tf}(\mathrm{Fe})$, equivalents given correspond to transferrin content within the DNA complexes] or iron-free apotransferrin (apo $\mathrm{Tf}$ ) were added to the tissue culture $30 \mathrm{~min}$ before the transfection. Serum-free medium was used during these experiments in order to eliminate possible iron sources. The resulting luciferase activity (corresponding to 500000 cells) is shown.

conjugates in HBS as specified in Figure 5. Complexes were used for gene delivery to $500000 \mathrm{~K} 562$ cells using standard conditions; aliquots of cell extracts standardized for protein content were assayed for resulting luciferase activity (see Figure 5).

Ternary complexes of DNA with transferrin-ethidium 


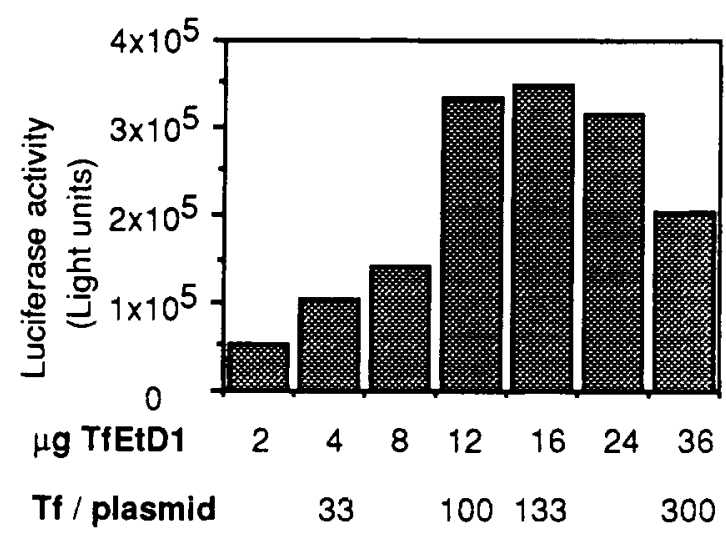

Figure 5. Transferrin-ethidium homodimer conjugates can mediate delivery and expression of the pRSVL luciferase gene. The transfections in K562 cells were performed with complexes of $6 \mu \mathrm{g}$ of $\mathrm{pRSVL}$ plasmid DNA with indicated amounts of transferrin-ethidium homodimer conjugates (fraction $1 ;$ TfEtD1) and assayed as described in Figure 3.

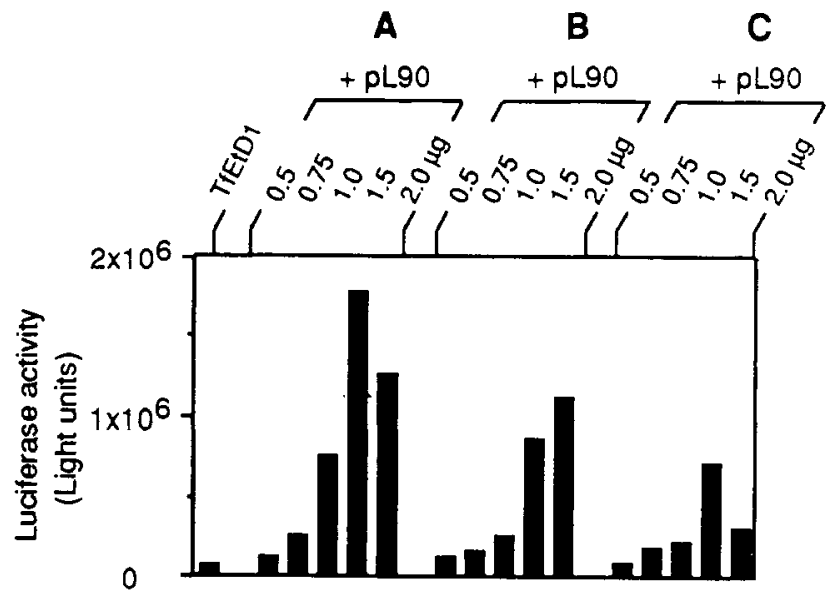

Figure 6. Transferrinfection with ternary complexes of pRSVL plasmid DNA, transferrin-ethidium homodimer conjugates (TfEtD), and various indicated amounts of polylysine ( $\mathrm{pL} 90$ ). The improvement in gene delivery is dependent on the ordering of mixing the three components: (A) first complexation of $6 \mu \mathrm{g}$ of DNA with $4 \mu \mathrm{g}$ of TfEtD and then addition of pL90; (B) addition of a mixture of TfEtD and pL90 to the DNA; (C) first complex formation of DNA with pL90 followed by TfEtD addition.

dimer conjugates and poly(L-lysine) with an average chain length of 90 lysine monomers (pL90, hydrobromide salt, Sigma) were prepared in three different modes: (1) Complexes were formed by first mixing a $170-\mu \mathrm{L}$ solution of $6 \mu \mathrm{g}$ of pRSVL DNA in HBS with a 170- $\mu \mathrm{L}$ solution of $4 \mu \mathrm{g}$ of TfEtD conjugates, and then mixing with a $170-\mu \mathrm{L}$ solutions of various amounts of pL90 in HBS as specified in Figure 6. (2) Complexes were formed by first mixing 170- $\mu \mathrm{L}$ solutions of $4 \mu \mathrm{g}$ of TfEtD conjugates with various amounts of pL90, followed by the addition to a $170-\mu \mathrm{L}$ solution of $6 \mu \mathrm{g}$ of pRSVL DNA. (3) Complexes were prepared by mixing a $170-\mu \mathrm{L}$ solution of $6 \mu \mathrm{g}$ of pRSVL in HBS with a 170- $\mu \mathrm{L}$ solution of various amounts of $\mathrm{pL} 90$ in HBS and subsequent addition of a $170-\mu \mathrm{L}$ solution of $4 \mu \mathrm{g}$ of TfEtD conjugates.

Gene delivery with the ternary complexes to K562 cells was performed as described above (see Figure 6).

\section{RESULTS}

Synthesis of Transferrin-Polylysine Conjugates with Linkage through the Transferrin Carbohydrate Moiety. The sequence of human serum transferrin (9), its glycosylation sites, and the structure of the carbohydrate parts (10) are known. The protein contains two identical carbohydrate chains that are attached by $\mathrm{N}$-glycosylation to Asn-413 and Asn-611. The glycan chains have a biantennary structure, composed of a mannotriosidodi- $N$ acetylchitobiose core bearing two $N$-acetylneuraminyl$N$-acetyllactosamine units. The glycosylation on the transferrin has no known influence on receptor binding or any other biological function (11) apart from the clearance of asialotransferrin from the plasma (12). Therefore we have chosen the transferrin carbohydrate moieties as the specific sites for attachment of polylysine and other nucleic acid binding domains, anticipating that this modification would not interfere with the binding of transferrin to its cellular receptor (see Figure 1).

Within the branched carbohydrate chains, sugars that contain a vicinal diol system can be oxidized by sodium periodate to yield aldehydes, with the concomitant cleavage of the $\mathrm{HOC}-\mathrm{COH}$ bond. In our procedure the iron-free form of human transferrin was treated with 15 molar equiv of sodium periodate at $0^{\circ} \mathrm{C}$ for $90 \mathrm{~min}$. Under similar low temperature conditions, in glycoproteins (13) as well as in the special case of human transferrin (14) the two terminal exocyclic carbon atoms of the sialic acids within the carbohydrate chains are selectively removed by periodate oxidation; this has been confirmed by the subsequent selective tritium incorporation into the modified sialic acid residues (14).

We coupled the oxidized form of transferrin through its aldehyde group to the amino groups of polylysine (average chain length of about 300 lysine monomers per molecule). The junction that results from aldimine formation was stabilized by reduction to the secondary amine with sodium cyanoborohydride, which is no longer hydrolyzable (see Figure 1 for details). The transferrin-polylysine conjugates were obtained after purification (as described below and in Experimental Procedures) in a satisfactory overall yield ( $50 \%$ or $62 \%$ based on transferrin or polylysine). Compared to the published procedure (1) this new synthesis has the advantage of being less time-consuming, and the synthesis is useful for the preparation of large amounts $(>100 \mathrm{mg}$ ) of conjugates with defined polycationtransferrin ligation sites.

Conalbumin Has No Sialic Acids and Does Not Form Polylysine Conjugates. Conalbumin (chicken egg transferrin) has been reported to lack sialic acids on the carbohydrate domain (15). We reinvestigated this in an assay with thiobarbituric acid (7). Accordingly conalbumin would not to be expected to function in ligation if the reaction is truly specific for the terminal sialic residues. Therefore, to test the specificity, we made several attempts with identical or slightly modified conditions. These did not yield significant amounts of conalbumin conjugates (less than $5 \%$ ), although, as in the case of the human transferrin, the periodate oxidation at $0^{\circ} \mathrm{C}$ or at room temperature produced some modified glycoprotein which showed staining with anisaldehyde that is characteristic for sugar aldehydes.

Although several sugars can be oxidized with periodate (at least at room temperature), the terminal sialic acid within the carbohydrate moiety of glycoproteins is especially suited for periodate oxidation and subsequent derivatization; the efficiency of the conjugation procedure as described in this paper seems to be strongly dependent on the presence of sialic acids.

Purification and Biological Properties of the New Conjugates. Isolation of the conjugates was performed by cation-exchange chromatography (Figure 2) with a salt gradient which allows fractionation into products with 
increasing polylysine to transferrin ratios. In previous experiments (1) the recovery of the products from this chromatographic step was only moderate as a result of irreversible binding of some polylysine-rich conjugate fractions to the resin. This problem could be solved by the addition of salt to the conjugate reaction mixture and loading the column at a high salt concentration $(0.75 \mathrm{M})$. With this modified procedure, not only was the yield of conjugates considerably increased but it could also be demonstrated that the recovered polylysine-rich conjugate fractions (with about one transferrin per 100 lysine moieties) are efficient in transferrinfection (16). Two main fractions, TfpL300A and TfpL300B, and a smaller fraction, TfpL300C, were obtained from the chromatographic purification of the new carbohydrate-linked conjugates (see Figure 2).

After loading of the transferrin ligands with iron (see Experimental Procedures), the new conjugates were tested for their ability to deliver pRSVL (8), a plasmid encoding $P$. pyralis luciferase as a reporter gene into the human K562 cell line in the same fashion as described in refs 3 and 16. A constant amount of $6 \mu \mathrm{g}$ of pRSVL plasmid DNA was mixed with increasing amounts of conjugate TfpL300A, TfpL300B, or TfpL300C in a set of titration experiments; for comparison, the most efficient conjugate fraction TfpL200C, previously prepared by ligation through disulfide linkage (16) was also included in these titration experiments. The complexes thus obtained were added to the K562 tissue culture in the presence of chloroquine (see Experimental Procedures), protein extracts of the transfected cultures were prepared after $24 \mathrm{~h}$ and assayed for luciferase activity (Figure 3 ). The presence of luciferase activity indicates that DNA has been successfully internalized by the cell, transported to the nucleus, and expressed as a gene. The carbohydrate-linked conjugates have high gene-delivery efficiency, similar or slightly better than those prepared by the initial method of disulfide linkage (Figure 3). The molar ratio of transferrin to polylysine influences the transferrinfection efficacy as was seen with the TfpL200 conjugates (16); the TfpL300B conjugate fraction with a ratio of transferrin to polylysine of $2.3 / 1$ was more active than either the polylysine-poor $\mathrm{A}$ fraction or the polylysine-rich $\mathrm{C}$ fraction.

In order to determine whether the internalization of the DNA complexes with the new conjugates proceeds via the transferrin receptor, complexes of $6 \mu \mathrm{g}$ of pRSVL with $18 \mu \mathrm{g}$ of TfpL300B were used for transferrinfection experiments in which $\mathrm{K} 562$ cells were treated with increasing amounts of either iron-loaded transferrin or iron-free apotransferrin (Figure 4). The presence of 3 or 30 equiv of iron-loaded transferrin results in a 10- or 100fold decrease in the gene delivery, respectively. The strong competition by free transferrin suggests that the uptake of the complexes occurs via the transferrin-specific entry pathway. Iron-free apotransferrin, due to its low receptor affinity (17), has far less influence on the transferrinfection.

Transferrin-Ethidium Dimer Conjugates as Novel DNA-Intercalating Gene-Delivery Agents. Polylysine was chosen as a DNA-binding element in the initial transferrin conjugates. We already have shown that it can be replaced by small polycationic peptides like salmon sperm protamine $(1,16)$. As an alternative to using charge interactions, as in polycation-DNA complexes, we are testing the utility of the strong intercalative binding interaction between a planar dye and DNA to attach transferrin to the nucleic acid. With the new procedure of coupling via the carbohydrate moiety, transferrin conju- gates with ethidium homodimer (EtD), a known efficient DNA intercalator (5), have been synthesized. We considered the carbohydrate chain to act as a spacer that should prevent steric hindrance of the intercalator by the large transferrin protein. The transferrin-ethidium homodimer conjugates (TfEtD) were isolated by removal of the unbound ethidium dimer by gel filtration followed by fractionation through chromatography on an hydrophobicinteraction column (phenyl-Sepharose). A small fraction of unconjugated transferrin eluted in the flowthrough whereas the transferrin conjugates remained on the column bound by hydrophobic interactions between the attached ethidium homodimer and the matrix. The conjugates were then isolated in two fractions by elution with buffer containing 2 or $3 \%$ octyl glucopyranoside.

A transferrinfection using standard conditions with the transferrin-ethidium dimer conjugates showed a significant gene expression in K562 cells (Figure 5), however at a moderate level compared to the most effective transferrin-polylysine conjugates. The maximum delivery was obtained at a DNA/conjugate ratio at which about 130 transferrin were bound to a single DNA plasmid. From previous work (16) it is known that plasmid DNA coated with about 10-20 polylysine-conjugated transferrin molecules can be efficiently internalized by the transferrin receptor mediated pathway, if the DNA is packaged to compact structures of a size of about $80-100 \mathrm{~nm}$ by the addition of further polycations. Therefore we prepared ternary complexes of the plasmid DNA with amounts of transferrin-ethidium dimer conjugates that represent about 30 transferrin molecules per DNA plasmid and various amounts of additional polylysine. As the ethidium dimer is not expected to condense DNA to a similar extent as polylysine, the lower activity of the transferrinethidium homodimer DNA complex is not surprising. If the DNA condensation is incomplete in the transferrinethidium homodimer complexes, then the addition of free polylysine, which causes a strong condensation of the DNA structure (18), should result in an increase in DNA delivery. As shown in Figure 6, the inclusion of polylysine results in improved gene delivery and expression. We observed that the order of mixing the three components influences the quality of the ternary complexes. The most deliverycompetent complexes were obtained if the attachment of the transferrin conjugates to the DNA preceded the binding of polylysine. Here, gene expression is more than 10-fold higher compared to that of complexes where polylysine is omitted from the complex formation (see Figure $6 \mathrm{~A}$ ). However, when the DNA was condensed with polylysine prior to the loading with the transferrin-ethidium homodimer conjugates gene expression is ca. 2-fold lower (see Figure 6C), probably the result of a less efficient binding of the transferrin-ethidium homodimer conjugates compared to the preparation used in Figure 6A.

\section{DISCUSSION}

We have described a simple and efficient procedure for the synthesis of transferrin-polylysine conjugates that is also suitable for the preparation of large quantities (100 $\mathrm{mg}$ or more) of conjugates. The two-step procedure is based on the selective oxidative modification and activation of the terminal sialic acids within the two welldefined carbohydrate moieties of human transferrin, followed by reductive coupling to the polylysine amino groups. Thus transferrin-polylysine conjugates are obtained with defined polycation-transferrin ligation sites with "nature-derived" carbohydrate spacers that are free of any modifications that might be derived from cross- 
linking agents. Consistent with the fact that the transferrin carbohydrate moiety has no influence on transferrin receptor binding, we found that the new TfpL conjugates can mediate gene delivery to the human erythroid K562 cell line with similar or greater efficiency than TfpL conjugates prepared with a heterobifunctional linking agent (1). Furthermore we show that the uptake of the DNA complexes with the new transferrin conjugates occurs via the transferrin receptor, because native iron-loaded transferrin, if added to the medium, efficiently competes for the uptake into the cells.

Because the avian ovotransferrin (conalbumin) lacks sialic acids in the carbohydrate part, the method does not function for the preparation of conalbumin-polylysine conjugates. However, we have successfully applied the procedure for the synthesis of polylysine conjugates with mouse transferrin and with a recombinant HIV glycoprotein gp120 (our unpublished results). We are exploring a second mode of binding Tf to DNA involving an intercalative dye. We have synthesized conjugates of human transferrin with the intercalator ethidium-homodimer that function as novel gene-delivery agents. If polylysine, which is known to condense DNA efficiently, to yield small toroid structures (18), is included in the complex formation, the transfection efficiency is considerably increased (Figure 6). DNA polylysine complexes without the transferrin conjugate, on the other hand show only negligible activity (16). Our results demonstrate that transferrin which is attached to DNA via an intercalating agent is sufficient for receptor-mediated gene delivery which may be further improved by condensation of the DNA with free polylysine.

\section{ACKNOWLEDGMENT}

We are grateful to Dr. Martin Nicklin for critical reading of the manuscript. We appreciate the technical assistance of Karin Kos.

\section{LITERATURE CITED}

(1) Wagner, E., Zenke, M., Cotten, M., Beug, H., Birnstiel, M. L. (1990) Proc. Natl. Acad. Sci. U.S.A. 87, 3410-3414.

(2) Zenke, M., Steinlein, P., Wagner, E., Cotten, M., Beug, H., and Birnstiel, M. L. (1990) Receptor-mediated endocytosis of transferrin polycation conjugates: An efficient way to introduce DNA into hematopoietic cells. Proc. Natl. Acad. Sci. U.S.A. 87, 3655-3659.

(3) Cotten, M., Langle-Rouault, F., Kirlappos, H., Wagner, E., Mechtler, K., Zenke, M., Beug, H., and Birnstiel, M. L. (1990) Transferrin-polycation-mediated introduction of DNA into human leukemic cells: stimulation by agents that affect the survival of transfected DNA or modulate transferrin receptor levels. Proc. Natl. Acad. Sci. U.S.A. 87, 4033-4037.

(4) Wu, G. Y., and Wu, C. H. (1987) Receptor-mediated in vitro gene transformation by a soluble DNA carrier system. J. Biol. Chem. 262, 4429-4432.

(5) Gaugian, B., Barbet, J., Oberlin, R., Roques, B. P., and LeP. ecq, J.-B. (1978) DNA bifunctional intercalators. 1. Synthesis and conformational properties of an ethidium homodimer and of an acridine ethidium heterodimer. Biochemistry 17, 50715078.

(6) Ellman, G. L. (1959) Arch. Biochem. Biophys. 82, 70.

(7) Uchida, Y., Tsukada, U., and Sugimori, T. (1977) Distribution of neuraminidase in Arthrobacter and its purification by affinity chromatography. J. Biochem. 82, 1425-1433.

(8) DeWet, J., Wood, K., DeLuca, M., Helinski, D., and Subramani, S. (1987) Firefly luciferase gene: structure and expression in mammalian cells. Mol. Cell. Biol. 7, 725-737.

(9) MacGillivray, R. T. A., Mendez, E., Shewale, J. G., Sinha, S. K., Lineback-Zins, J., and Brew, K. (1983) The primary structure of human serum transferrin. J. Biol. Chem. 258, 3543.

(10) Dorland, L., Haverkamp, J., Schut, B. L., Vliegenthart, J. F. G., Spik, G., Strecker, G., Fournet, B., and Montreuil, J. (1977) The structure of the asialo-carbohydrate units of human serotransferrin as proven by $360 \mathrm{MHz}$ proton magnetic resonance spectroscopy. FEBS Lett. 77, 15-20.

(11) Huebers, H. A., and Finch, C. A. (1987) The physiology of transferrin and transferrin receptors. Physiol. Rev. 67, 520582.

(12) Regoeczi, E., Chindemi, P. A., Debanne, M. T., and Hatton, M. W. C. (1982) Dual nature of the hepatic lectin pathway for human asialotransferrin type 3 in the rat. J. Biol. Chem. 257, 5431-5436.

(13) Lenten, L. V., and Ashwell, G. (1971) Studies on the chemical and enzymatic modification of glycoproteins. J. Biol. Chem. 246, 1889-1894.

(14) Kishimoto, T., and Tavassoli, M. (1986) Double labeling of transferrin: tritium labeling of sialic acid and ${ }^{225 I}$ or ${ }^{60} \mathrm{Fe}$ labeling of the protein moiety. Anal. Biochem. 153, 324-329.

(15) Williams, J. (1968) A comparison of glycopeptides from the ovotransferrin and serum transferrin of the hen. Biochem. $J$. $108,57-67$.

(16) Wagner, E., Cotten, M., Foisner, R., and Birnstiel, M. L. (1991) Transferrin-polycation DNA complexes: the effect of polycations on the structure of the complex and DNA delivery to cells. Proc. Natl. Acad. Sci. U.S.A. 88, 4255-4259.

(17) Dautry-Varsat, A. D., Ciechanover, A., and Lodish, H. F. (1983) $\mathrm{pH}$ and the recycling of transferrin during receptormediated endocytosis. Proc.Natl. Acad.Sci.U.S.A.80, 22582262.

(18) Laemmli, U.K. (1975) Characterization of DNA condensates induced by poly(ethylene oxide) and polylysine. Proc. Natl. Acad. Sci. U.S.A. 72, 4288-4292. 